\title{
THEORETICAL AND EXPERIMENTAL
}

\section{STUDIES OF CHURN FLOW IN VERTICAL TUBES}

\section{A Final Technical Report}

\author{
for
}

\section{Research Carried out Under Sponsorship of DOE Contract DE-ACO3-84SF12198}

\author{
at \\ The University of Houston \\ Department of Chemical Engineering \\ Houston, Texas 77004
}

\section{DISCLAIMER}

This report was prepared as an account of work sponsored by an agency of the United States Government. Neither the United States Government nor any agency thereof, nor any of their employees, makes any warranty, express or implied, or assumes any legal liability or responsibility for the accuracy, completeness, or usefulness of any information, apparatus, product, or process disclosed, or represents that its use would not infringe privately owned rights. Reference herein to any specific commercial product, process, or service by trade name, trademark, manufacturer, or otherwise does not necessarily constitute or imply its endorsement, recommendation, or favoring by the United States Government or any agency thereof. The views and opinions of authors expressed herein do not necessarily state or reflect those of the United States Government or any agency thereof. 


\section{DISCLAIMER}

This report was prepared as an account of work sponsored by an agency of the United States Government. Neither the United States Government nor any agency Thereof, nor any of their employees, makes any warranty, express or implied, or assumes any legal liability or responsibility for the accuracy, completeness, or usefulness of any information, apparatus, product, or process disclosed, or represents that its use would not infringe privately owned rights. Reference herein to any specific commercial product, process, or service by trade name, trademark, manufacturer, or otherwise does not necessarily constitute or imply its endorsement, recommendation, or favoring by the United States Government or any agency thereof. The views and opinions of authors expressed herein do not necessarily state or reflect those of the United States Government or any agency thereof. 


\section{DISCLAIMER}

Portions of this document may be illegible in electronic image products. Images are produced from the best available original document. 


\section{TABLE OF CONTENTS}

Page

\section{INTRODUCTION}

Transitional Behavior

Mechanisms of Transition From Slug Flow

Stable Slug Length

3

Insights into Mechanism Based on Wall Shear Stress Measurements

Void Fraction Measurements for the Study of Mechanisms Space Average Void Fraction 


\section{INTRODUCTION}

The state of knowledge of the mechanics of two phase flow has made major advances in the past five years. The modern approach to predicting hydrodynamic and thermal performance of such systems is based on this sequence.

- Predict the flow pattern from physically based models which control the transitions.

- For each flow pattern define the fundamental mechanisms that are operative and construct sound hydrodynamic models.

- Once these hydrodynamic models exist, they are extended to create models which incorporate heat and mass transfer.

At the present time reasonably reliable models exist for the prediction of these flow pattern transitions for vertical and near vertical pipe flow. Although further studies will be needed, there is indication these models can properly account for fluid properties and line size. The patterns which exist in such vertical systems are: bubbly, slug, churn and annular. Free flowing geothermal wells are known to operate over the entire flow pattern range. Thus it is necessary to predict pressure drop and heat transfer rates for each pattern.

Recent work has provided preliminary models for the bubbly and churn flow patterns so that it is possible to calculate the holdup and frictional pressure drop for these two patterns from physically based models. Other details of the flow such as bubble size, slug length and velocity, bubble length, as well as other characteristics of slug flow can now be predicted.

Considerable research is now going on for annular flow in several laboratories around the world. As a result modelling of friction and heat transfer for this flow pattern can be expected to advance considerably over the next few years. 
The pattern know as churn flow has received little or no attention. This is probably largely because it is a highly unsteady pattern with stochastic features and is extremely complex. However, calculations show that for many goethermal wells the condition of churn flow consists over much of the length of the two phase zone. Furthermore, it frequently exists at the surface so that design of separation equipment and surface piping depends on the accurate modelling of this type of flow.

It has been the long term purpose of this project to develop physically based models for churn flow which can be used as a basis for predicting holdup, frictional loss and heat transfer rates for this flow pattern in geothermal systems. To achieve this end, it was necessary to develop new methods for measuring the time dependent characteristics of the flow and thus be able to uncover the basic physics of the flow. Models can then be developed based on this understanding which characterizes the flow and equations for holdup, friction and heet transfer evolved.

This report summarizes the work accomplished in the first year of this project. The overall plan calls for a 3-4 year program to reach the final objective of understanding churn flow sufficiently to be able to constuct reliable model equations for the flow mechanics.

\section{TRANSITIONAL BEHAVIOR}

The churn flow pattern exists between the conditions of slug and annular flow. Assume stable slug flow takes place in a vertical tube at one pair of gas and liquid rates. If the gas flow is increased eventually the slugs will become unstable. At this condition the existence of a uniform upward propagation velocity of the slugs on Taylor buble can no longer be detected. Large lumps of liquid fall down because they are unsupported by the gas phase. The liquid accumulates at the bottom of the tube and is blown up intermittently, a situation characteristic of churn flow.

Now consider high gas rates where annular flow exists. If the gas rate is gradually reduced a point is reached where churn flow is again observed. Thus the 
churn flow pattern is bounded at the low gas rates by slug flow and high rates by annular flow. An example of a flow pattern map which shows the location of churn flow is shown in Fig. 1.

The first question is to determine the mechanism of transition. Clearly the transition between annular and churn is quite different than that between slug and churn. It is important to understand these transition mechanisms because they define the limiting behavior of the churn flow model.

\section{MECHANISMS OF TRANSITION FROM SLUG FLOW}

Three possible mechanisms exist for this transition. Consider stable slug flow as pictured in Fig. 2. Taylor bubbles rise up the tube moving faster than the flowing liquid. A liquid film falls down around the Taylor bubble mixing with the slug that follows. This process of counterflow and remixing is characteristic of stable slug flow. As the gas rate is increased and the transition takes place three possible mechanisms seem possible.

(1) The gas rate in the Taylor bubble becomes high enough that the interfacial shear becomes significant. Flooding can then take place. The film is suspended and flow reversal exists characteristic of churn flow.

(2) As the gas rate is increased the void fraction in the liquid slug just behind the Taylor bubble increases sufficiently that coalescence takes place. Large vapor pockets form in the liquid slug, the competent liquid bridge is destroyed and the liquid falls, causing churning to initiate.

(3) The slug length decreases. These lengths are too short to establish fully developed velocity distributions behind the Taylor bubble. Overtaking occurs. Each time one slug overtakes another the combined liquid cannot be supported by the gas and it falls, giving rise to churn flow. 
Part of the work discussed in this report presents experimental studies attempting to discern which mechanism is applicable.

\section{STABLE SLUG LENGTH}

An analytical study was undertaken to determine the stable slug length. Experimental observations for water-air systems in vertical upward suggest that the stable slug length, $\ell_{s}$, is relatively insensitive to the gas and liquid flow rates and is fairly constant for a given tube size. The minimum stable slug length for upward flow in vertical tubes has been observed to be of about 16-25D (Fernandes et al., AIChE J., $\underline{29}, 981,1983$ ). Barnea et al. (AIChE J., $\underline{26}, 34 \dot{5}, 1980$ ) suggested that the minimum stable slug length is related to the distance needed to reestablish the normal turbulent velocity distribution in the liquid slug after it is disturbed by the falling liquid film entering at its front. The mixing process between the films and slug was simulated by a wall jet entering a large reservoir. The purpose of the present study is to incorporate the concepts of periodic relaxation and recovery of a wall boundary layer within $\dot{a}$ slug for determining the stable slug length.

A schematic description of the physical concepts associated in upward slug flow is given in Fig. 3. Under the conditions of fully developed flow, successive Taylor bubbles and liquid slugs rise steadily. An idealized axisymmetric flow is considered. The Taylor bubble almost bridges the conduit, leaving a thin counter-current falling film. The falling film merges into the liquid slug, which travels upward overtaking the thin film. Thus, the fluid in the liquid film is continuously picked up by the fast moving slug and is accelerated to the fluid velocity in the liquid slug, forming a mixing eddy which penetrates a distance $\ell_{m}$ into the slug front. Simultaneously with this pick-up process the slug sheds liquid from its back, around the nose of the next Taylor bubble thus forming the next falling film. Clearly, when the rate of liquid pick-up at the front equals the rate of liquid shed at the rear the length of the slug stabilizes. 
The concept of a mixing vortex at the front accomplished by a shedding process at the back implies a recurrent development of the momentum boundary layer in the slug. The boundary layer adjacent to the wall is periodically destroyed (or distorted) in the mixing region at the front of the slug and is reestablished (or recovered) in the body of the slug behind the mixing region. As the thickness of the boundary layer approaches the radius of the pipe $\delta \simeq D / 2$ a fully developed velocity profile is established which is the same for all liquid slugs, long enough for this to happen. The rate of advance of a Taylor bubble depends on the centerline velocity in the liquid of the preceding slug. If adjacent slugs are each long enough to have $\delta \simeq D / 2$, then the centerline liquid velocities are the same, adjacent Taylor bubbles will advance at the same speed and no overtaking will take place. The result will be stable slug flow. However, in the entry region short high frequency slugs exist of variable length. These slugs are too short for the boundary layer thickness to be fully developed, as is shown in Fig. 1(c). As a result, the centerline liquid velocities preceding successive Taylor bubbles are different. Since the rise velocity of the bubble nose depends on the liquid velocity at the rear part of the slug core, $\mathrm{v}_{\mathrm{t2}}$, which is sustained by the undeveloped slug is different from $v_{t 1^{*}}$. When two such slugs merge as a result of overtaking, a single slug is created, whose length is approximately the sum of the two. This process continues (if the entry distance is long enough) until the length of all slugs is greater than that needed to create the fully developed profile associated with $\delta=D / 2$. If the minimum stable slug length is designated as $\ell_{s}$, then the slug lengths observed should be that resulting from the merger of two slugs one of which at least is shorter than $\ell_{s^{\circ}}$ Thus, slug lengths observed in the fully developed region should be practically greater than $\ell_{\mathrm{s}}$ 


\section{The Governing Equations}

Figure $3(a)$ shows the process of mixing and boundary layer redevelopment presented in a stationary coordinate system. At $x=0$ the local velocity is uniform and equal to $V_{\text {LLS }}$ - At increasing $x$ the velocity distribution consists of $v=v(y) y \leq \delta$ and $v=V_{0}$ for the outer regions. The corresponding picture in a coordinate system moving upward with a velocity, $v_{t}$, is shown in Fig. 3(b). . The boundary layer velocity is $u(y)$ and the outer velocity is $\mathrm{U}_{0^{\circ}}$

In a moving coordinate system the integral forms of the momentum equations for the boundary-layer region and the external flow are respectively:

$$
\begin{aligned}
& \frac{d}{d x} \int_{0}^{\delta} 2 \pi(R-y) u^{2} d y-U_{0} \frac{d}{d x} \int_{0}^{\delta} 2 \pi(R-y) u d y=\frac{2 \pi R \tau w}{\rho} \\
& -\frac{\pi\left[R^{2}-(R-\delta)^{2}\right]}{\rho} \frac{d P}{d x} \\
& U_{0} \frac{d}{d x} \int_{0}^{\delta} 2 \pi(R-y) u d y+\frac{d}{d x}\left[(R-\delta)^{2} U_{0}^{2}\right]=-\frac{(R-\delta)^{2}}{\rho} \frac{d P}{d x}
\end{aligned}
$$

where

$$
-\frac{d P}{d x}=\rho g_{x}-\frac{d p}{d x}
$$

and

$$
\rho \simeq \rho_{L}\left(1-\alpha_{L}\right)
$$

$\alpha_{L S}$ is the gas holdup within the liquid slug and $R$ is the tube radius. Note that the momentum of the gas bubbles within the liquid slug has been neglected since $\rho_{G} \ll$ $\rho_{L}$. Equation (2) is the integral form of the Euler equation for the external flow region and can be reduced to its differential form: 
$U_{0} \frac{\mathrm{dU}_{0}}{d x}=-\frac{1}{\rho} \frac{d P}{d x}$

Substituting the following non-dimensional variables:

$$
\begin{array}{ll}
n=r / R=\frac{R-y}{R} ; & x=x / D \\
\Delta=\delta / R ; & \xi=\frac{u}{\nabla_{t}}\left(\text { and } \xi_{0}=\frac{U_{0}}{\nabla_{t}}\right)
\end{array}
$$

Eqs. $(1,4)$ read, respectively:

$$
\begin{aligned}
& \frac{d}{d X} \int_{1-\Delta}^{1} \xi^{2} n d \eta-\xi_{0} \frac{d}{d X} \int_{1-\Delta}^{1} \xi n d \eta=\frac{2 \dot{\tau} w}{v_{t}^{2}}-\frac{(2-\Delta) \Delta}{2 \rho v_{t}^{2}} \frac{d P}{d X} \\
& \xi_{0} \frac{d \xi_{0}}{d X}=-\frac{1}{\rho v_{t}^{2}} \frac{d P}{d X}
\end{aligned}
$$

Note that the pressure term can be eliminated by combining Eqns. $(6,7)$. These equations can now be combined with overall volumetric balances between the conduit entry and any cross-section in the slug and with an assumed nth power distribution law in the boundary layer to yield, of ten considerable algebraic manipulation

$$
\begin{aligned}
\{(1-\Delta)+ & \frac{n}{(n+2)}\left(1-\xi_{0}\right)\left(1-2 \Delta+\frac{n}{(n+1)} \Delta\right)-\frac{n}{(n+1)}\left(2-\xi_{0}\right)\left[1-2 \Delta+\frac{2 n \Delta}{(2 n+1)}\right\} \\
& \left(1-\xi_{0}\right) \frac{d \Delta}{d X}+\left\{\frac{n}{(n+1)} \Delta\left(1-\xi_{0}\right)\left(1-\Delta+\frac{n}{(2 n+1)} \Delta\right)-\frac{2 n}{n+2}\left(1-\xi_{0}\right)\right. \\
& \left.\left(1-\Delta+\frac{n}{2(n+1)} \Delta\right)\right\} \Delta \frac{d \xi_{0}}{d X}=\frac{2 \tau_{w}}{\rho v_{t}^{2}}-\frac{\Delta(2-\Delta)}{2 \rho v_{t}^{2}} \frac{d P}{d X}
\end{aligned}
$$

where the pressure term is determined by Eq. (7). The wall shear stress, $\tau_{w}$, is obtained locally (based on the 7 th power law) by:

$$
\frac{\tau_{w}}{\rho}=0.0225 \mathrm{v}_{0}^{2}\left(\frac{{ }_{L}}{\delta V_{0}}\right) 1 / 4
$$


Integration of Eqn. (8) with the initial condition $\delta=\delta_{0}$ at $x=0\left(\Delta=\Delta_{0}\right.$ at $X=$ 0) yields the local boundary-layer thickness, local velocity profile (with local $\mathrm{V}_{0}$ or $\mathrm{U}_{0}$ ) and local pressure gradient as functions of position, $x$. This is continued until $\Delta=1.0$ and the length, $\mathrm{X}$, at which this takes place defines the stable slug length.

Figure 4 shows a comparison of the theory with the experimental data of Fernandes (Ph.D. Dissertation, University of Houston, 1981). The prediction for ( $\left.\ell_{S} / D\right)$ minimum and twice that value are shown for a sequence of possible values of voids in the liquid slug. The Fernandes data are shown as circles. These measurements were made in a vertical plexiglass tube, $0.0507 \mathrm{~m}$ in diameter and $11.1 \mathrm{~m} \mathrm{long}$, using airwater. The data covered the full range of flow rate space for which the slug flow pattern was observed. For these data $\alpha_{\text {LS }}$ varied from about 0.24 to 0.29 .

As shown in Fig. 4, all experimental average slug lengths are higher than the minimum stable slug length predicted by the theory. Any combination of two slugs, one of which (at least) being shorter than the minimum stable length, may be involved in the overlapping process taking place at the entry region. Thus, the most probable slug length is larger than the minimum stable slug length and less than two times the minimum length. Indeed, all experimental values are confined between the minimum slug length and twice that length. Note that the comparison in Fig. 4 does not take into account the length of the mixing region at the front of the slug. The theoretical results are in reasonable accord with the data.

\section{INSIGHTS INTO MECHANISM BASED ON WALL SHEAR STRESS MEASUREMENTS}

\section{WALL SHEAR PROBE}

A method has been developed on the simultaneous measurement of the size and direction of wall shear stress. The objective was to explore the direction of the flow at the wall during churn flow. The initial condition of the importance of the quantity was obtained from measurements of the pressure drop during transition from annular 
to churn flow using air-water in the $\mathbf{5 . 1}$ diameter test section shown in Fig. 5 . The measured pressure gradient as a function of gas and liquid rate is shown in Fig. 6. A definite minimum exists and to the left of the minimum we observe churn flow. Since the pressure gradient is directly as the wall shear, we proceeded to develop a method for dynamic shear measurement.

The wall shear stress measurement method is based upon the diffusion controlled electrolysis technique developed by Reiss and Hanratty (AIChE J., 8, 245, 1962). According to this method the local wall shear stress is deduced from a mass transfer coefficient on a small element of the pipe surface. The mass transfer coefficient is determined electrolytically; the small surface element forms one electrode (cathode), and a much larger electrode (anodes) is placed elsewhere in the system. The following redox chemical reaction is used

$$
\begin{aligned}
& \mathrm{Fe}(\mathrm{CN})_{6}^{3-}+\mathrm{e} \rightarrow \mathrm{Fe}(\mathrm{CN})_{6}^{4-} \text { at the cathode } \\
& \mathrm{Fe}(\mathrm{CN})_{6}^{4-}+\mathrm{Fe}(\mathrm{CN})_{6}^{3-}+\mathrm{e} \text { at the anode }
\end{aligned}
$$

This technique is illustrated in Fig. 7. By applying a constant voltage, within the polarization voltage range of the redox system used, the concentration of the ferricyanide ions at the cathode surface falls to zero level and a concentration boundary layer is formed. The thickness of this layer is estimated to be $10^{-3}$. Since the Schmidt number for this system is of the order of $10^{3}$, the concentration boundary layer is well within the hydrodynamic boundary layer. Fluctuations in electric current reflect local velocity gradient fluctuations in a region well within the viscous sublayer.

For the situation shown in Fig. 7 the wall stress can be related to the mass transfer coefficient through a solution of the convective diffusion equation to give $\tau_{w} \sim k_{c}^{3}$, where $k_{c}$ is measured directly from the current flow in the cell.

This basic method required modification for the case where the direction of the stress changed with time. The technique consisted of using two closely spaced 
electrode with parallel circuits. The mass transfer in the downstream electrode can be shown to always be less than that upstream. Thus by making two measurements simultaneously the location of the smaller one always designates the direction. The circuit used for each channel is shown in Fig. 8.

The results of applying this method to the 7 flow conditions shown in Fig. 9 appear in Figs. 10 and 11. The remarkable result is that the shear stress switches in a random way from upward to downward in the region of the left of the pressure drop minimum, is uniformly negative in the region to the right of the minimum and is near zero at the minimum. Thus churn flow is characterized by regular changes in flow direction at the wall. The numbers on the curves of Fig. 6 indicate the fraction of the time the wall stress is downward directed.

These data are now being utilized to construct new mathematical models for churn flow.

\section{VOID FRACTION MEASUREMENTS FOR THE STUDY OF MECHANISMS}

\section{SPACE AVERAGE VOID FRACTION}

The test section was equipped with three fast closing values which were pneumatically operated. Under a range of conditions which covered the entire flow rate space for churn flow average void fractions were measured. The void in the two spaces between the three values were simultaneously determined. These values are

tabulated as $\alpha_{1}$ and $\alpha_{2}$ in the table which follows. Recently (Fernandes, Semiat and Dukler, AIChE J., 29, 981, 1983) a theoretical model was developed for predicting average void fraction during slug flow. This model consists of a 18 equation network which expresses each of the physical processes which control the flow. These equations were solved for each of the conditions shown in the tables and the results shown these as well. In Fig. 12 a graphical comparison appears. The result is quite remarkable. The average void can be predicted within $10 \%$ of measured values by the 
theory thus strongly suggesting that churn flow is a situation of degenerated slug flow. This provides valuable insights to mechanism and these results are now being pursued in modelling of churn flow.

\section{CROSSECTIONAL AVERAGE VOIDS}

This method for measuring dynamic void fraction uses a microwave resonant cavity built around a section of the pipe through which the two-phase flow is to be measured; the pipe walls of this section must be of non-electrical conductive material. Since the resonant frequency of a cavity is related to the magnitude and volume. distribution of dielectric material within the cavity and since the liquid has a dielectric constant different from air, the resonant frequency of the cavity system will be, in general, a function of volume of the liquid "within" the cavity. The relationship between the volume of liquid in the cavity and the resonant frequency of the cavity system is extremely important. To be a useful measuring technique for two-phase flow, the resonant frequency of the cavity must be uniquely related only to the total volume of liquid within the cavity; it must not be volume distribution or volume geometry sensitive.

\section{Theoretical Considerations}

Cavity measurements are generally techniques which are based on rigorous solutions of the electromagnetic field problem. Such a solution is possible only when the dielectric volume geometry in context with the cavity geometry is sufficiently simple. Furthermore, the measurements are made under the assumption that the cavity resonates in a specific mode at the time of the measurement. While this latter criteria can be met, the volume geometry for two-phase flow measurement is unknown and indeed will be different at each instant of time and consequently a rigorous solution of the measurement problem is not possible. 
However, there is a measurement method based upon valid approximations which appears to be applicable to the solution of the measurement problem. This method is based on the cavity perturbation technique for the measurement of dielectric constants of arbitrary sample shapes introduced in a resonant cavity. This technique involves approximations in the formulation which lead to acceptable results only under very restricted conditions: The sample volume must be very small compared with the cavity itself so that a frequency shift which is small compared with the resonant frequency of the empty cavity is produced by the insertion of the sample. Also since the fields assumed in the sample are usually the solutions of static problems, certain sample dimensions must be small compared with the wavelength, or the unperturbed field in the sample region must be uniform (Sucher and Fox, 1963).

Cavity perturbation measurements can be, highly accurate and the approach makes it unnecessary to account for many of the details of the cavity since these are the same with and without the sample and hence tend to cancel out, since the different of the two cavity conditions is the significant result. Perturbation techniques also permit the measurement of dielectric samples of small size and of various shapes.

The basic cavity perturbation formula from which specific results can be derived is:

$$
\frac{f_{2}-f_{1}}{f_{2}}=\frac{\int v_{c}\left[\left(\mu_{2}-\mu_{1}\right) H_{1} \cdot H_{2}-\left(\varepsilon_{2}-\varepsilon_{1}\right) E_{1} \cdot E_{2}\right] d v}{\int v_{c}\left(\varepsilon_{1} E_{1} \cdot E_{2}-\mu_{1} H_{1} \ell H_{2}\right) d v}
$$

where

$f_{1}=$ resonant frequency of the cavity without the sample

$f_{2}=$ resonant frequency of the cavity with the sample

$v_{c}=$ volume of the cavity 
$\mathrm{H}_{1}, \mathrm{E}_{1} \mu_{1} \varepsilon_{1}=$ cavity parameters without the sample

$\mathrm{H}_{2}, \mathrm{E}_{2} \mu_{2} \varepsilon_{2}=$ cavity parameters with the sample

The case of interest is for cavity 1 to be empty so that $\varepsilon_{1}=\varepsilon_{0} \mu_{1}=\mu_{0}$; the sample is homogeneous and non-magnetic so that $\varepsilon_{2}$ is constant and real, and $\mu_{2}=\mu_{0}$; and the volume of the sample $v_{s}$ is very small compared to $v_{c} \cdot$ For these conditions, the equation becomes

$$
\frac{f_{2}-f_{1}}{f_{2}}=\left(\frac{\varepsilon_{2}}{\varepsilon_{0}}\right)-1 \frac{\int v_{s} E_{1} \cdot E_{2} d v}{\int v_{c}\left|E_{1}\right|^{2} d v}
$$

It should be noted that the field $E_{1}$ in the empty cavity is presumed known and only the perturbed field $\mathrm{E}_{2}$ in the sample volume $v_{S}$ remains unknown.

In the preceding discussion, the technique assumed a single sample volume placed in the cavity. Obviously, this is not the case for the liquid volume that is to be measured. However, a number of investigators have considered the problem of obtaining an "average field approximation" for dielectries containing a random concentration of randomly oriented identical shaped inclusions of another dielectric material. The results of these studies indicate that the dielectric property of the mixture can be considered in terms of an "effective dielectric constant" that is a linear function of the ratio of the volume of the particles to the volume of the host medium. This linear relationship is valid under the conditions that the particle volume concentration is small and that the largest dimension of the particle shape is very small compared to the wavelength of the electromagnetic field.

\section{Experimental System Design}

It is seen from the above discussion that a rigorous analysis of the proposed measurement technique is not possible. It also appeárs that the perturbation technique 
could be used to obtain the void measurments provided the required conditions can be met in the practical system. The major conditions are:

1. The maximum volume of liquid in the cavity must be small compared to the volume of the cavity. The important aspect of this volume limitation is that the change in the cavity resonant frequency due to this volume of liquid must be small, about $0.1 \%$.

2. The electric field throughout the volume to be occupied by the liquid must be uniform.

3. The electric field in the volume to be occupied by the liquid should be the same with and without the liquid; that is, $E_{1}=E_{2}$ in Eqn. 11. Note that for this condition, Eqn. 11 becomes

$$
\frac{f_{2}-f_{1}}{f_{2}}=\left(\frac{\varepsilon_{2}}{\varepsilon_{0}}-1\right) \frac{\int v_{s}\left|E_{1}\right|^{2} d v}{\int v_{c}\left|E_{1}\right|^{2} d v_{1}}=\left(\frac{\varepsilon_{2}}{\varepsilon_{0}}-1\right) K v_{s}
$$

where $\mathrm{K}$ is a constant that is a function of the cavity geometry.

The main question that must be answered is how closely must these conditions be met to provide a practical measuring system. The question can only be answered by essentially building an analog model of the proposed system and performing specific measurements relating to the two-phase flow conditions.

A cavity system was designed which was anticipated to satisfy to a reasonable degree the various requirements outlined previously. The system consists of a rectangular resonant cavity $24^{\prime \prime} \times 24^{\prime \prime} \times 0.5^{\prime \prime}$ wide with an entry hole in the center through which the pipe penetrated. The resonant frequency of the cavity is measured by making the cavity the frequency determining element of a microwave oscillator; hcraee, the oscillation frequency is the resonant frequency of the cavity. To function 
as a dynamic void measurement system, the oscillating frequency would be measured continuously (or sampled at a sufficiently high rate), converted to an analog voltage proportional to the change in frequency and recorded as a function of time.

The rectangular cavity was selected because the fundamental resonant mode, $\mathrm{H}_{101}$, can be readily coupled to the external oscillator circuitry, the higher modes of oscillation are sufficiently above the fundamental mode so that multimoding can be avoided and the electric field configuration within the cavity can be readily related to the required field condition. The cavity depth or thickness was kept small so that the effective cross-section of the flow that was "within the cavity" was small. It is obvious that the field across the center hole in the cavity will not be uniform and consequently the effect of this non-uniformity on the frequency relationship would have to be determined by experimental measurements. The cavity was made of aluminum of sufficient thickness to provide a mechanically rugged and stable cavity.

The oscillator circuit was built around the metal-ceramic triode 7462 electron tube. This tube provided sufficient signal output to drive directly the frequency counter used to measure the frequency of oscillation. The oscillator circuit diagram is shown in Fig. 13.

\section{Experimental Measurements}

Several measurements were taken on the cavity before the oscillator circuit was designed. For these measurements the cavity resonant frequency was determined by measuring the frequency response curve of the cavity using a variable frequency signal generator and a voltimeter. While the accuracy of this technique was limited, it did provide the important preliminary information that the electrical losses in the cavity due to the finite conductivity of the aluminum cavity walls were negligible, a reasonably linear relationship existed between the dielectric volume within the cavity and the change in resonant frequency, and that for measurements with the dielectric 
sample placed in the hole area the resonant frequency change appeared to depend upon the position of the sample within the area.

After the oscillator circuit was completed, measurements were made to verify the linear relationship between the volume of dielectric material placed within the cavity and the change in resonant frequency. Measurements were made with various shapes and sizes of plexiglass $\left(\varepsilon / \varepsilon_{0} \approx 3.4\right)$ that were fitted within the cavity through the center hole. Solids plexiglass pieces as well as thin plexiglass walled discs and rings filled with water $\left(\varepsilon / \varepsilon_{0} \approx 80\right)$ were used. The shapes were made of uniform crosssection with a length equal to the cavity depth; consequently, the electric field relationship $E_{1}=E_{2}$ was essentially satisfied for these measurements.

The results of these measurements indicate that the resonant frequency change of the cavity is dependent only on the total volume of dielectric material in the cavity; this volume can be made up of a single sample or several individual samples having a random geometrical relationship (see Figs. 14 and 15 ).

Extensive measurements were made placing the dielectric samples in the hole area cross-section. The results of these measurements indicate the following:

1. The field strength across the hole area is not uniform and varies rapidly near the cavity edges (see Fig. 16). The field was measured by using a voltimeter and probe and it was determined that the field in the area near the center of the hole is essentially uniform but reduced in strength relative to the field .. inside the cavity; the reduction was approximately an order of magnitude.

2. For solid plexiglass samples placed within the "uniform field" area of the hole, the relationship between the resonant frequency change and the volume of dielectric material is reasonably linear and essentially independent of the geometry. 
3. For water samples placed within the same hole area as the plexiglass the relationship between the change in resonant frequency and the volume showed some significant departure from linearity and was somewhat dependent upon the volume geometry.

4. Since the perturbation technique assumes that the difference between the cavity electromagnetic field configuration for the two conditions of measurements is only slightly changed, the value of the dielectric constant of the material as well as the volume must be considered. Specifically, in the case of water, which has a realtive dielectric constant of 80 , the frequency shift, $f_{2}-f_{1}$, is more indicative of having met the perturbation requirements than the volume.

5. The change in resonant frequency is a function of the length of the dielectric column in the hole area (see Fig. 17). This length extends several inches beyond the center-plane of the cavity and is a function of the dielectric constant of the material. The extensiveness of this sensitivity was not anticipated.

A variety of attempts to modify the circuit and the cavity have not eliminated this problem and the reading continues to be sensitive to the approach of liguid slugs from below. It may be necessary to design a completely different shaped cavity to overcome this problem. 'This work is continuing. 
Comparison of Theoretical and Experimental Void Fraction

Flow Pattern: Churn Flow $\quad$ (Page 2 of 2)

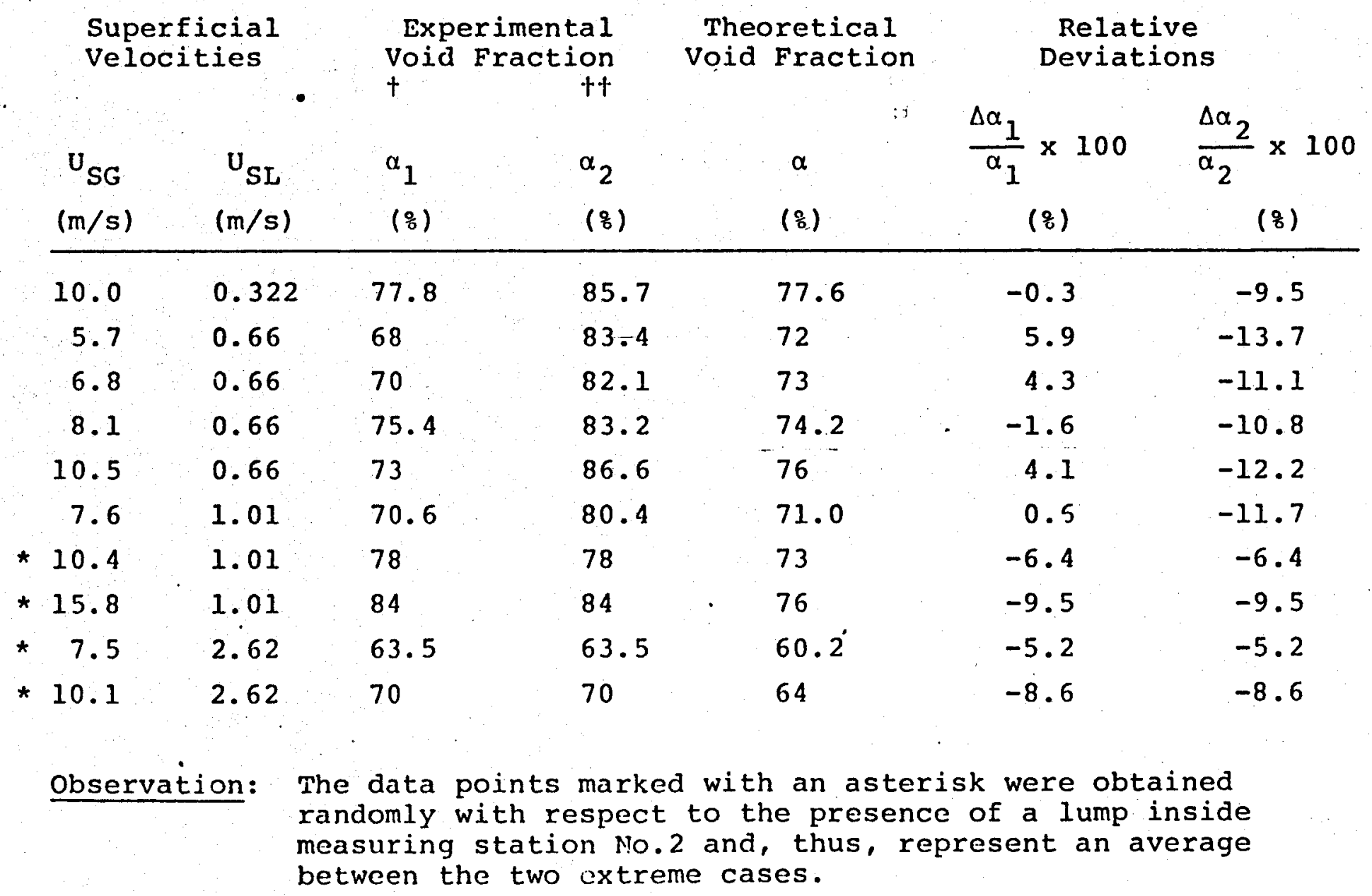




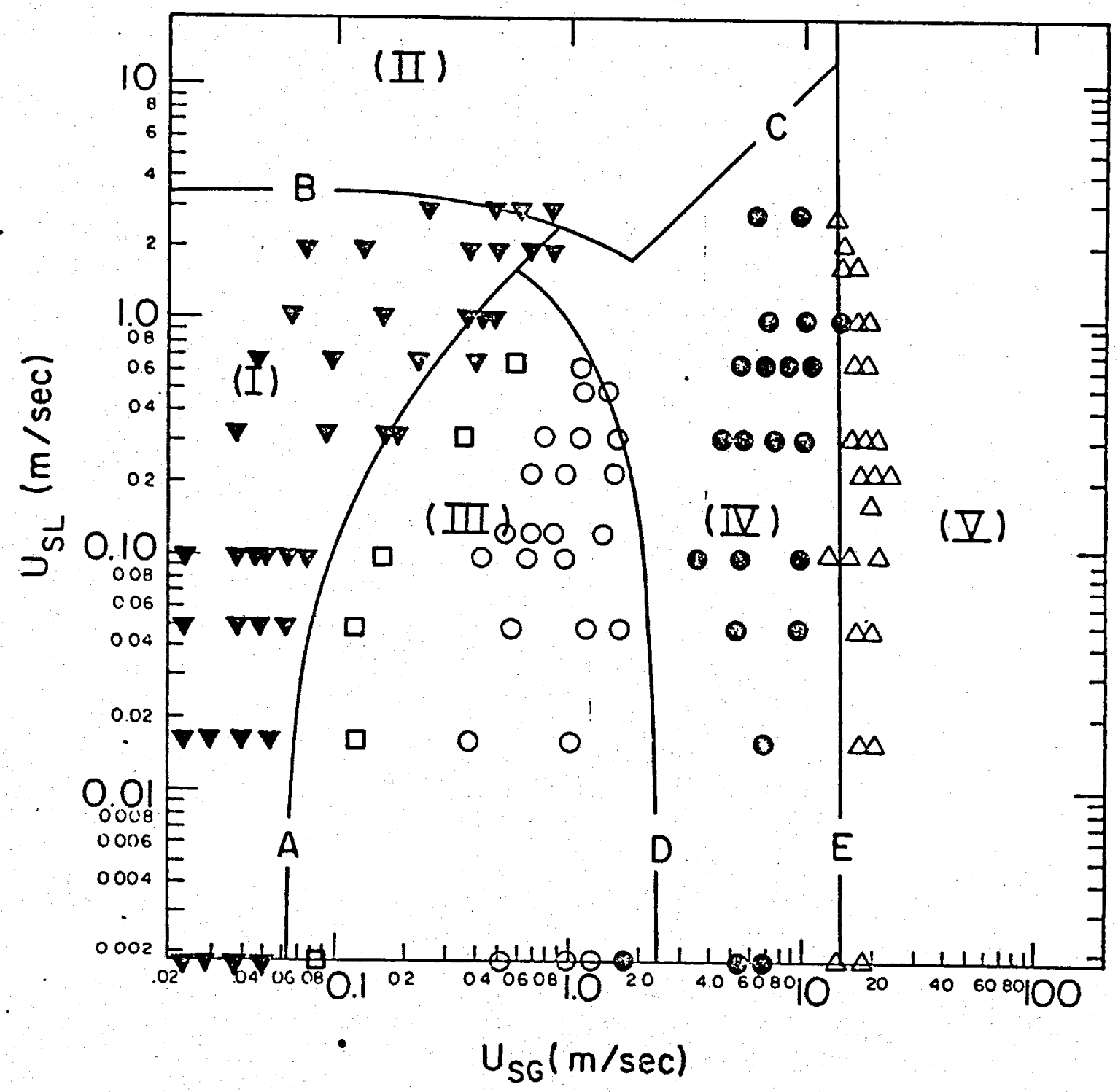

FIGURE 1

TYPICAL FLOW PATTERN MAP: VERTICAL UPFLOW I, II=BUBBLE; III=SLUG; IV=CHURN; $\mathbb{Z}=$ ANNULAR 


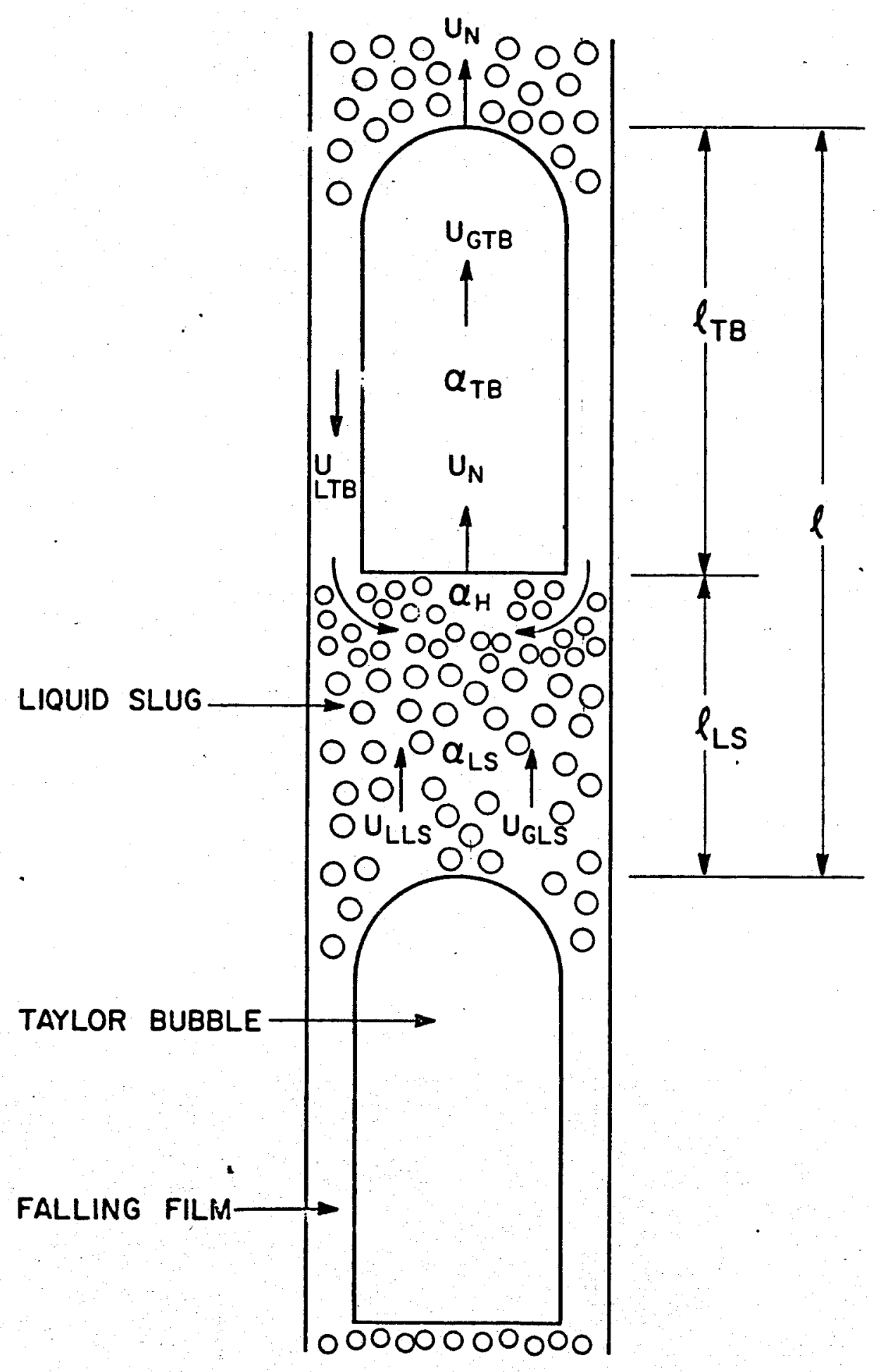

FIGURE 2

PHASE DISTRIBUTION \& FLOW IN A SLUG UNIT 


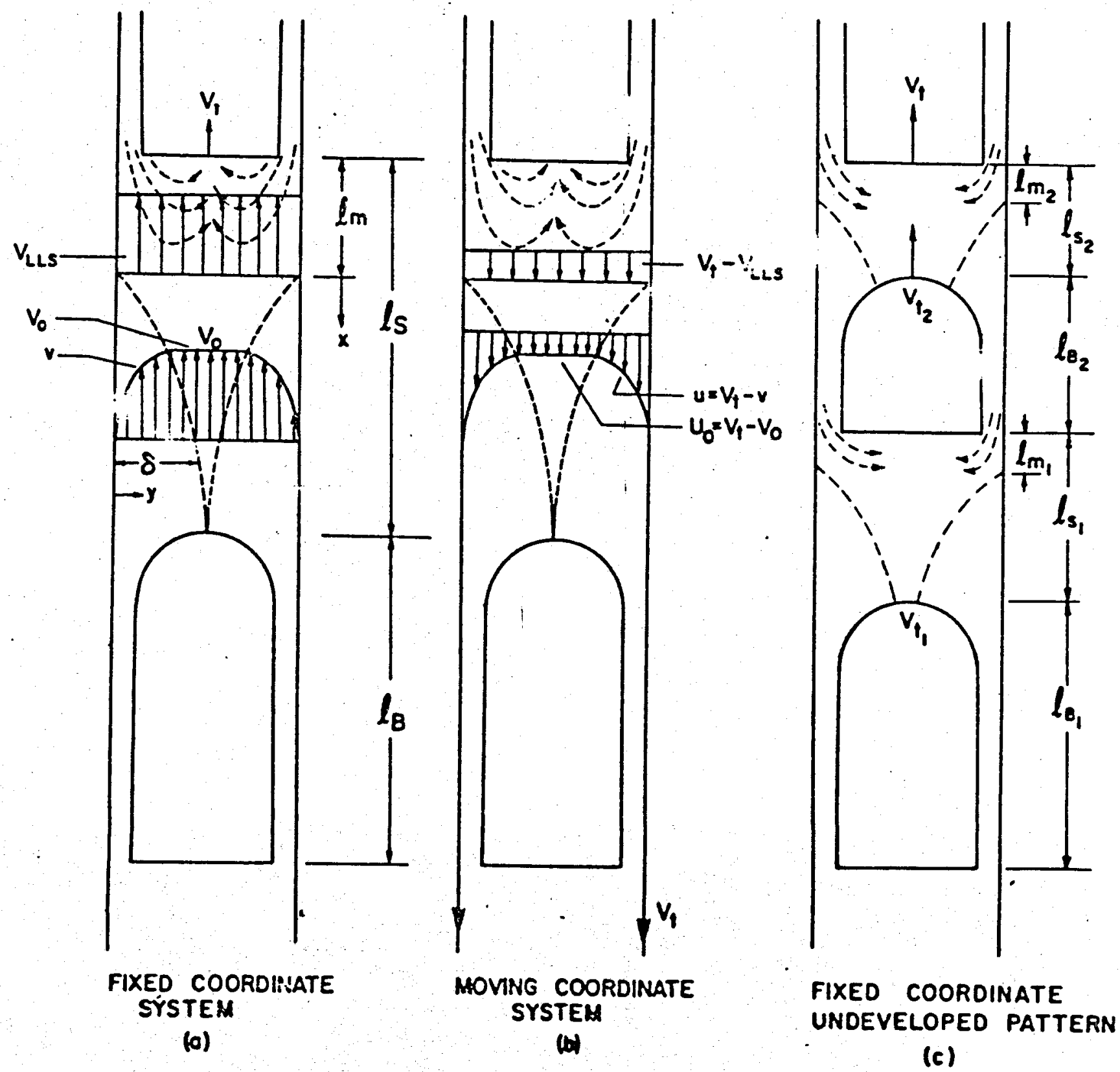

FIGURE 3 BOUNDARY LAYER DEVELOPMENT 


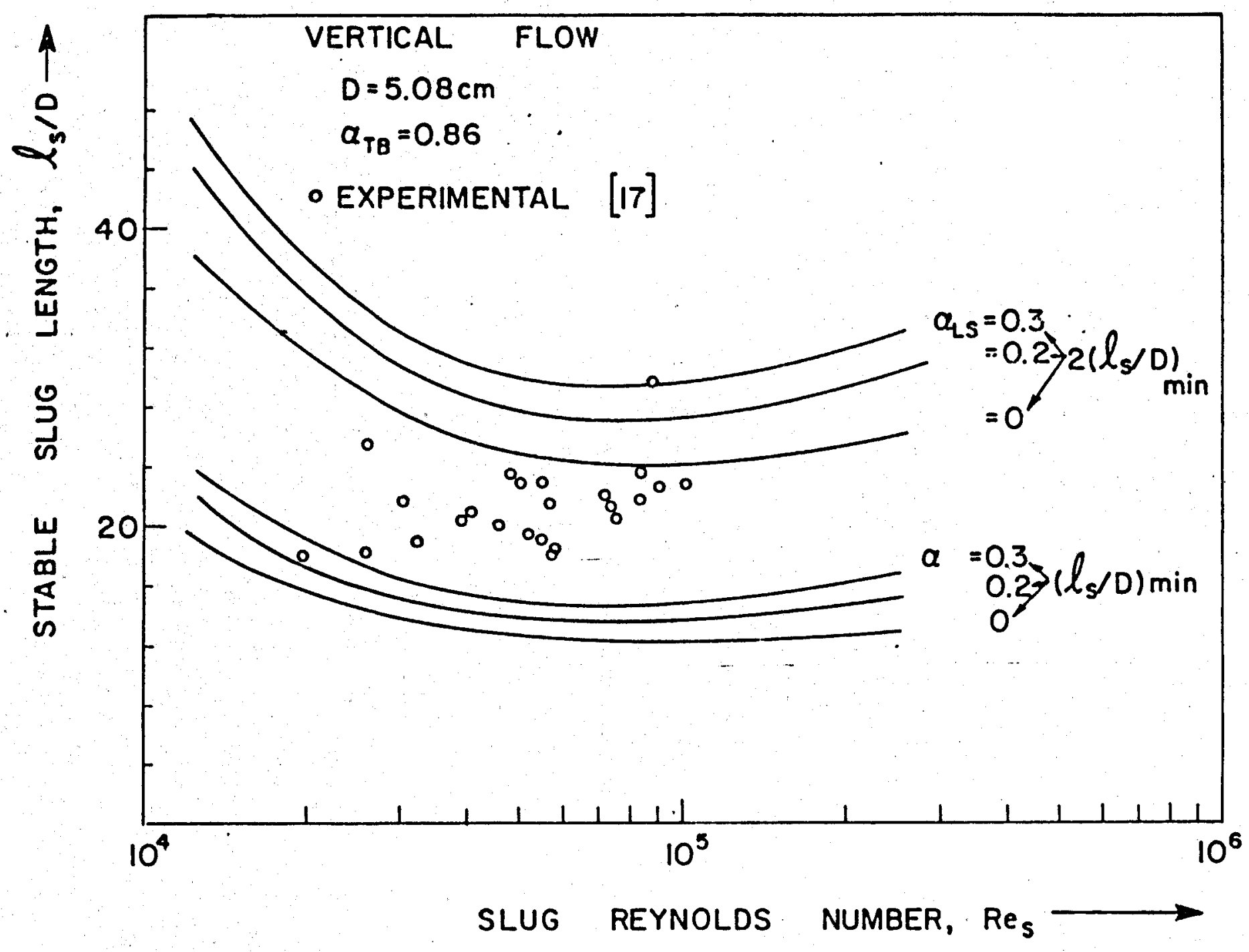

FIGURE 4

COMPARISON OF EXPERIMENTAL AND THEORETICAL SLUG LENGTHS 


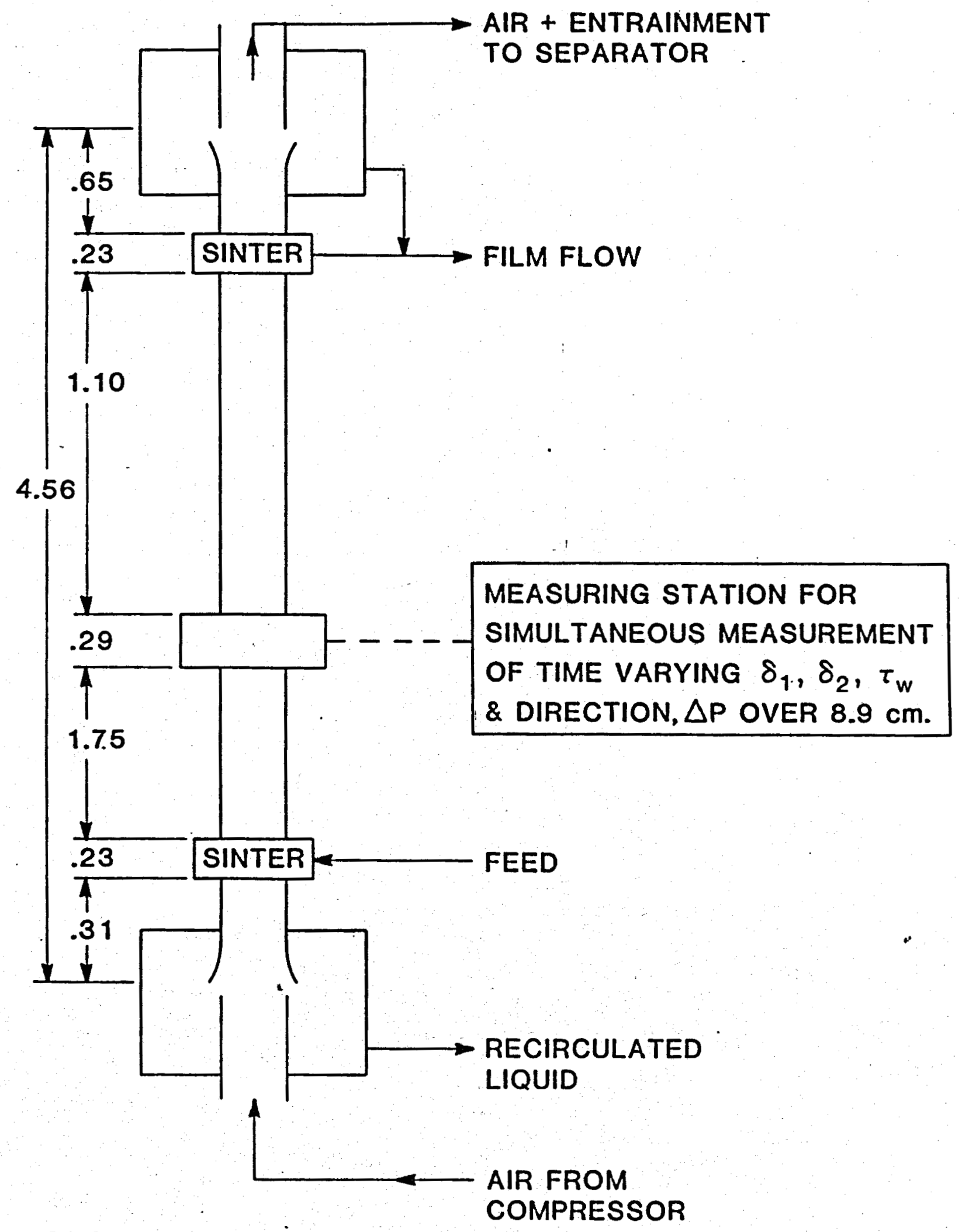

FIGURE 5

CONFIGURATION FOR STUDYING FILM FLOW ABOVE THE FEED (DISTANCES IN METERS) 
FIGURE 6

PRESSURE GRADIENT

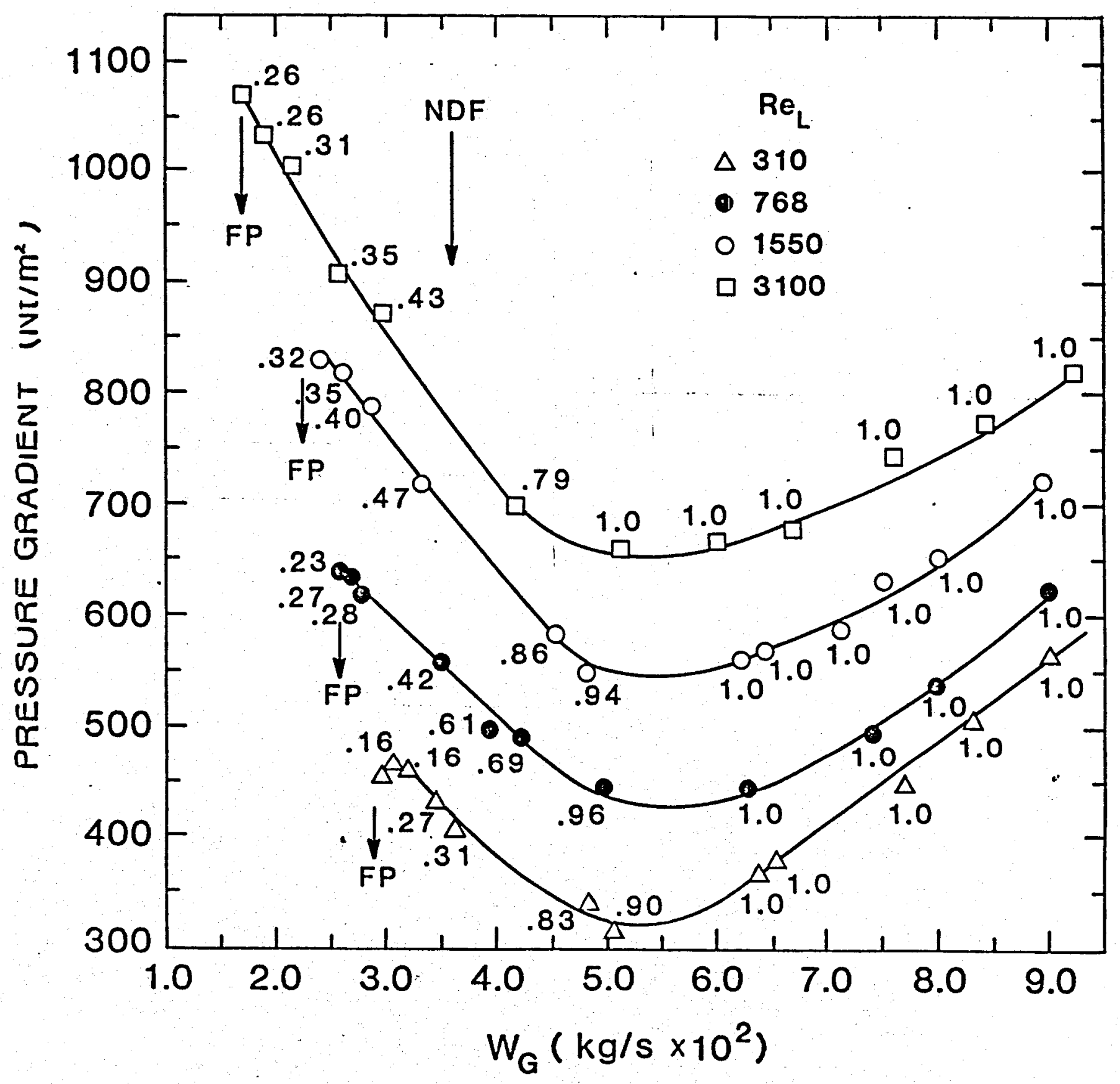




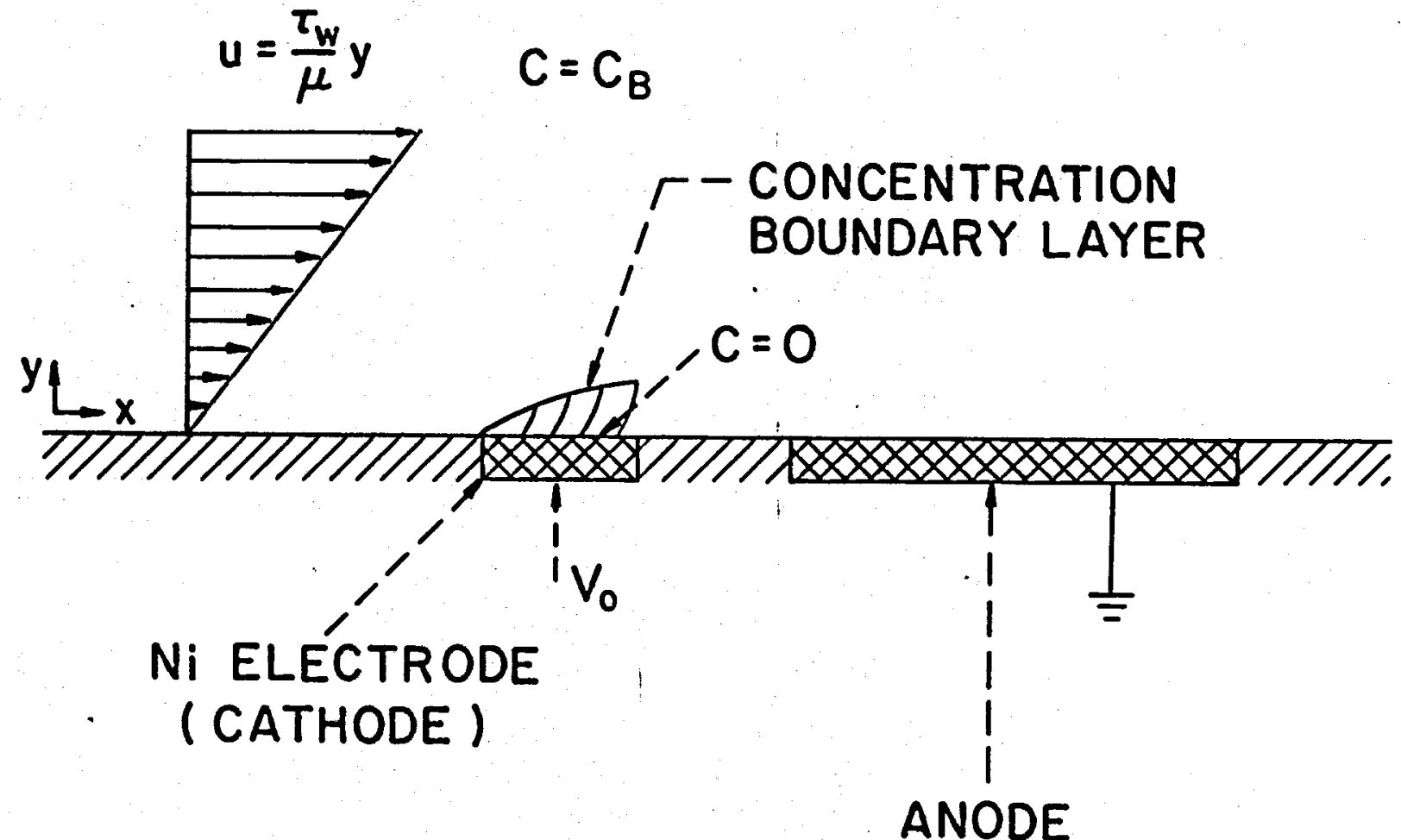

FIGURE 7

DESCRIPTION OF THE ELECTROCHEMICAL TECHNIQUE 


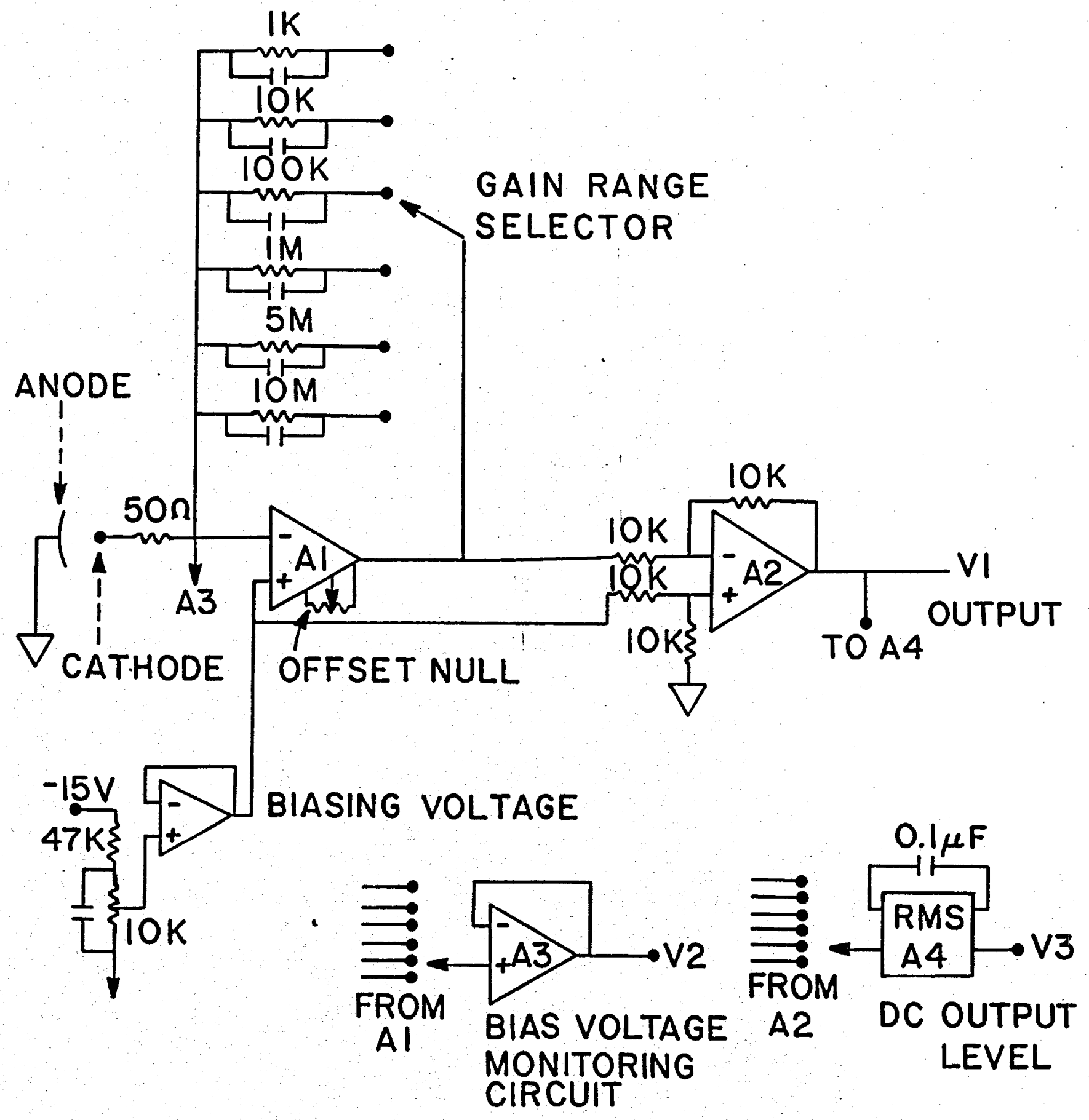

FIGURE 8

WALL SHEAR STRESS MONITORING CIRCUIT 


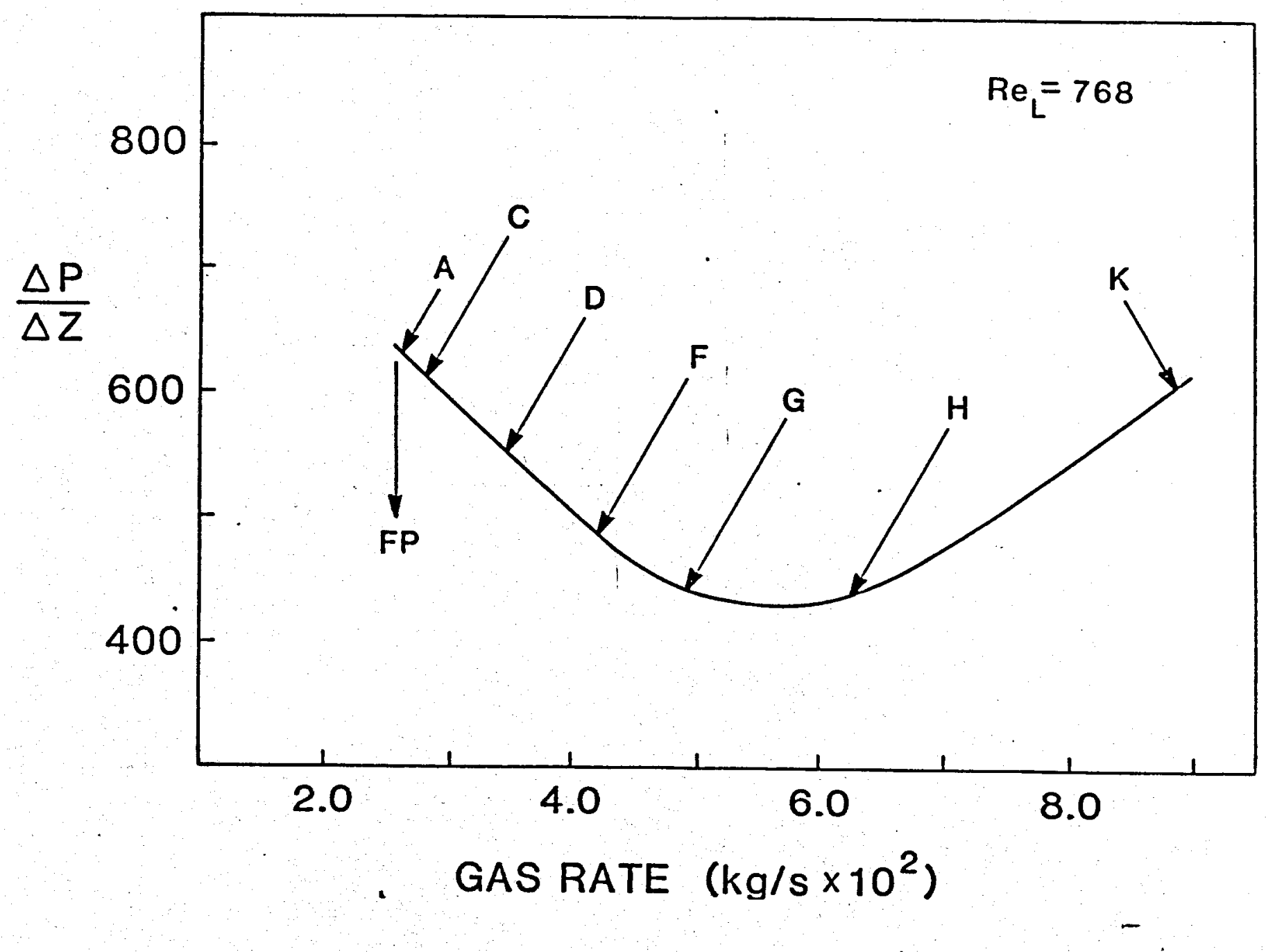

FIGURE 9

FLOW CHA FM FLOW CONDITIONS USED TO STUDY, WALL SHEAR STRESS 


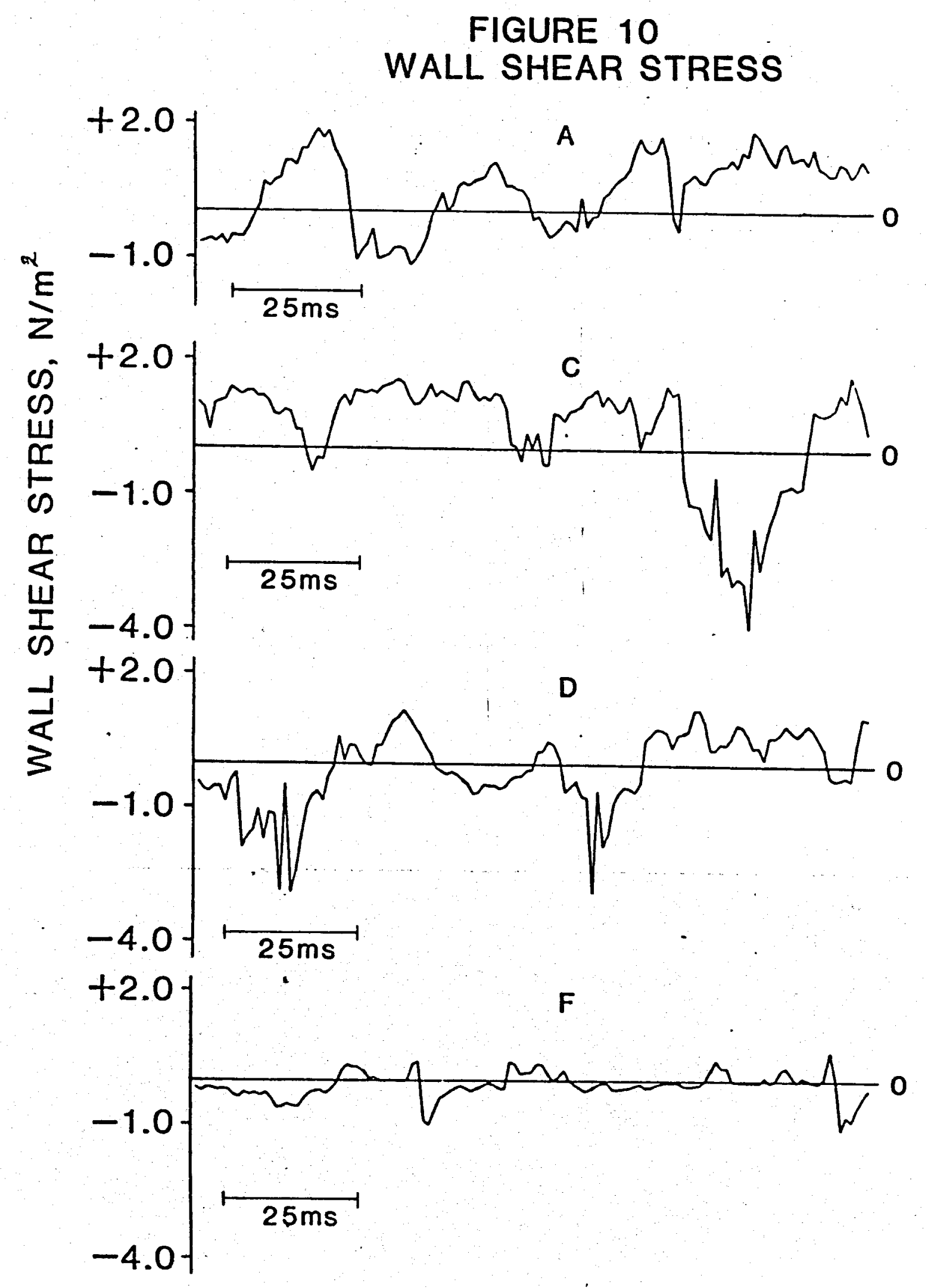




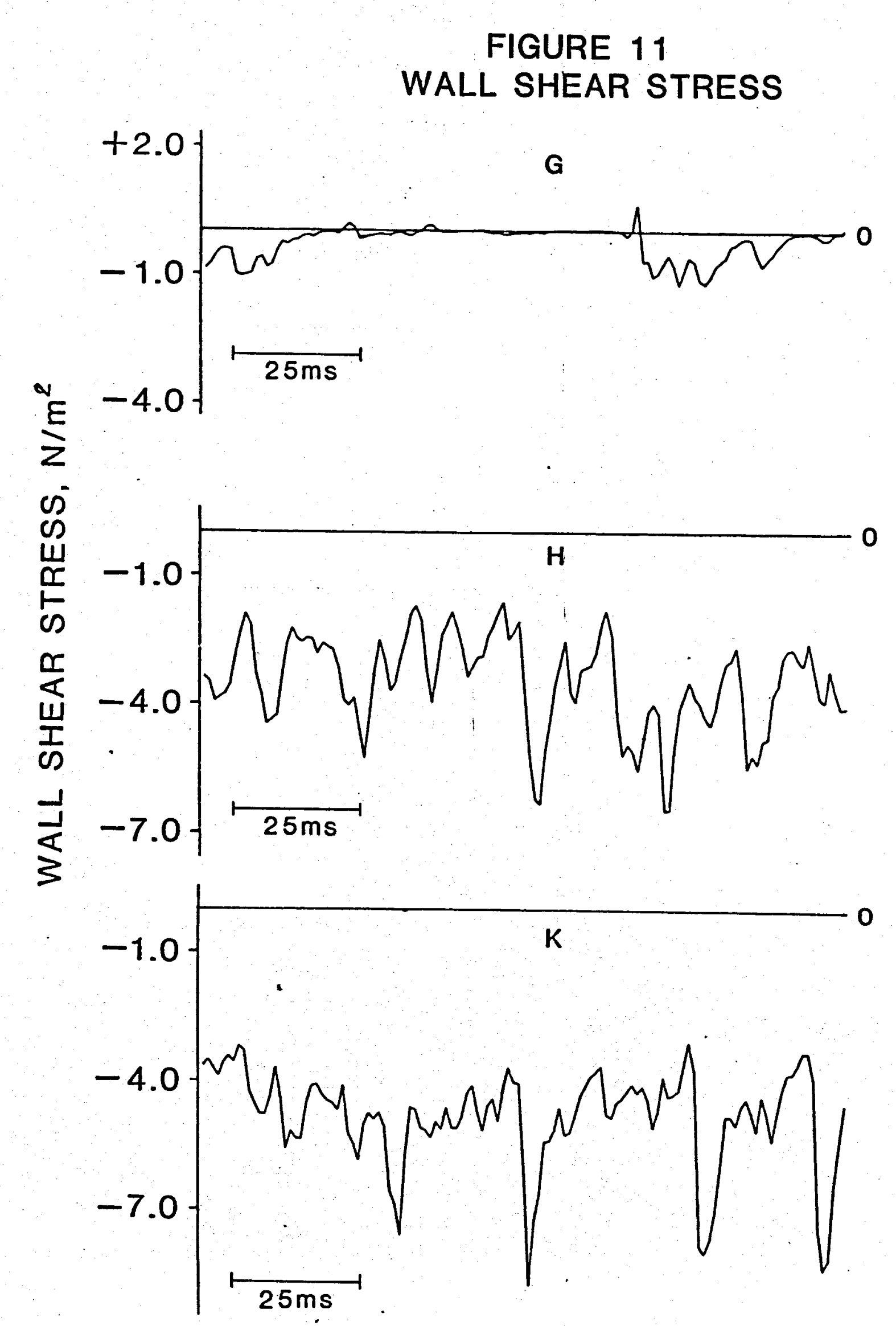




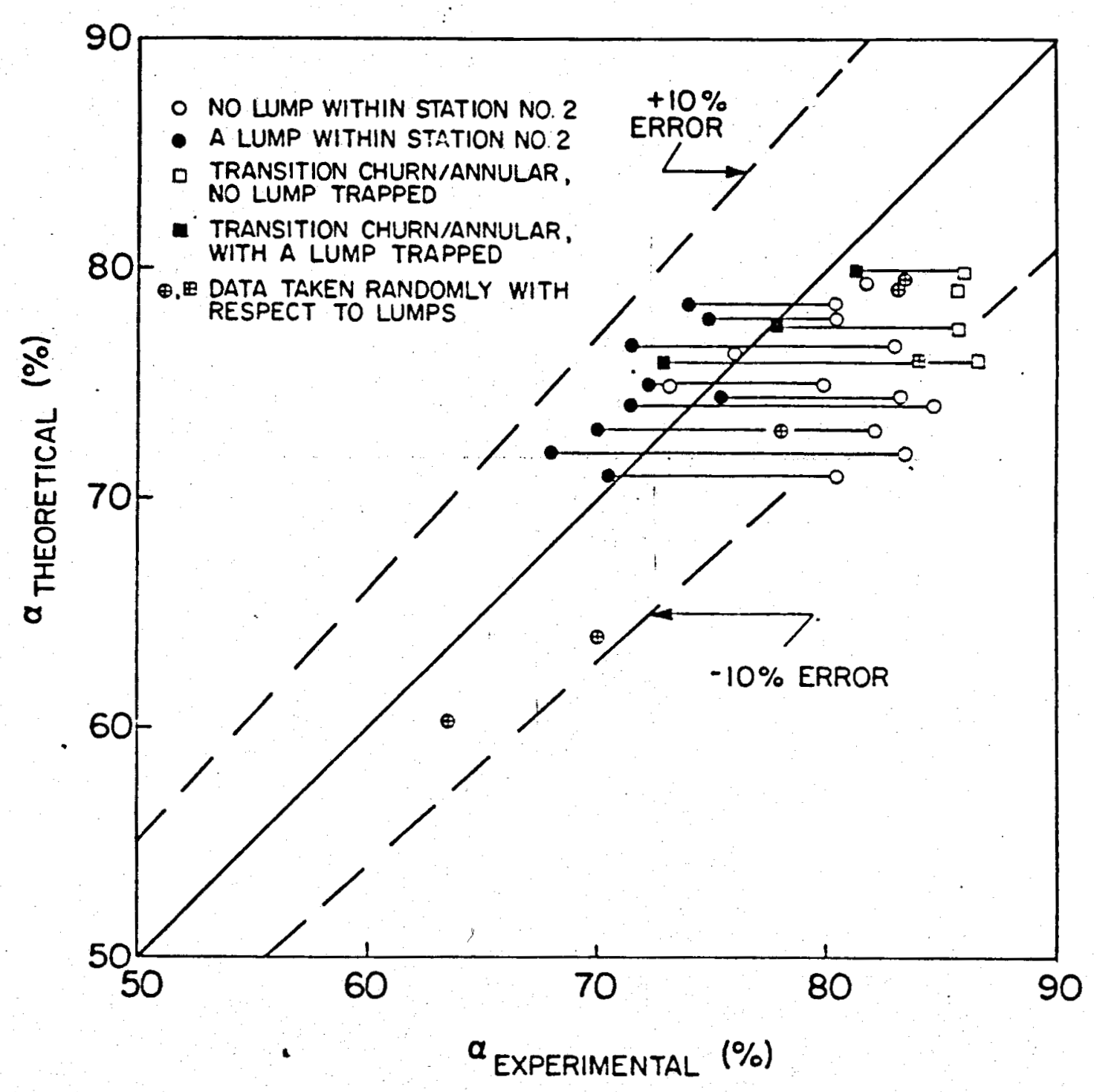

\author{
FIGURE 12 \\ COMPARISON OF THEORETICAL AND \\ EXPERIMENTAL VOIDS DURING CHURN FLOW
}




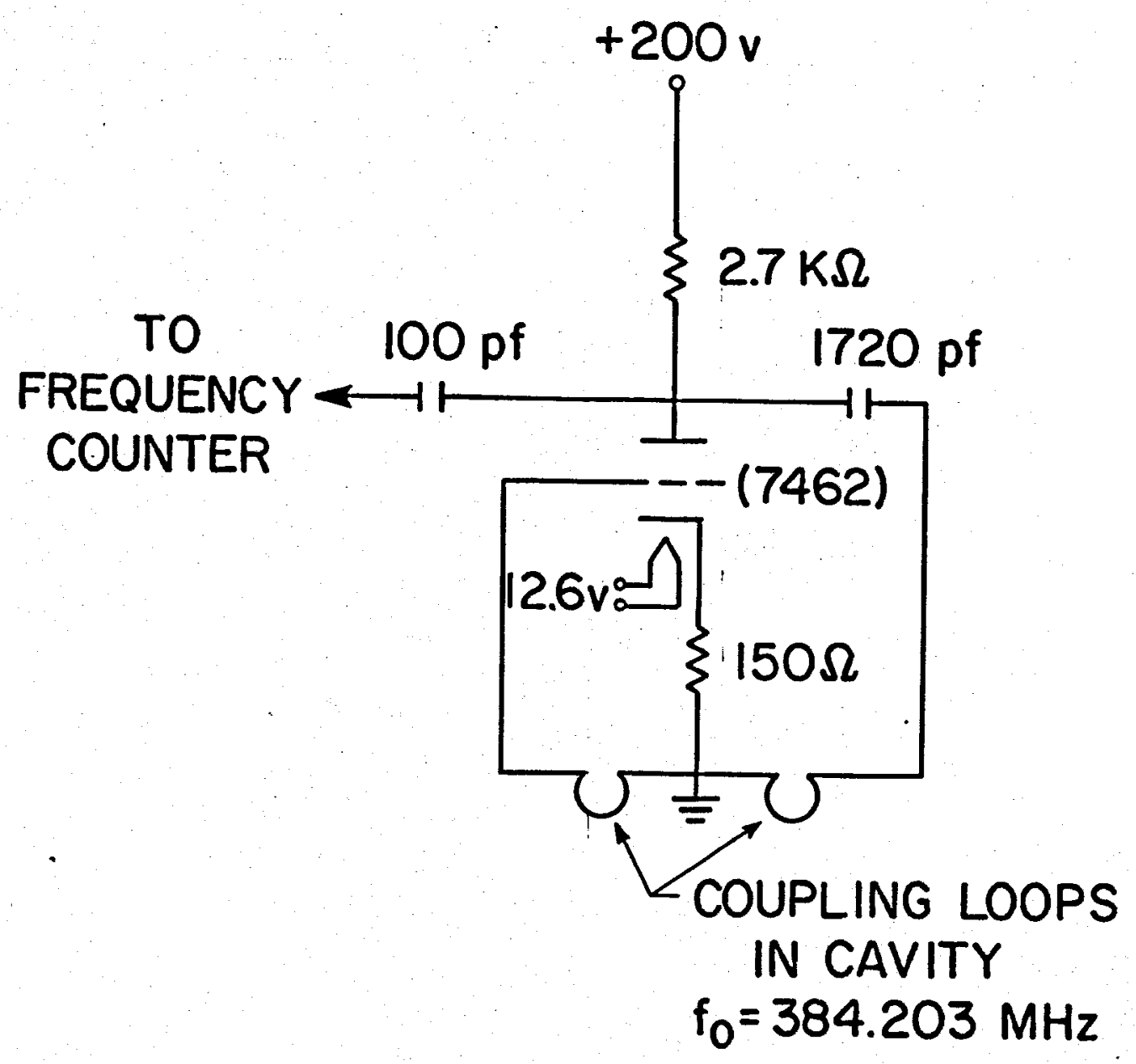

FIGURE 13

CAVITY OSCILLATOR CIRCUIT DIAGRAM 


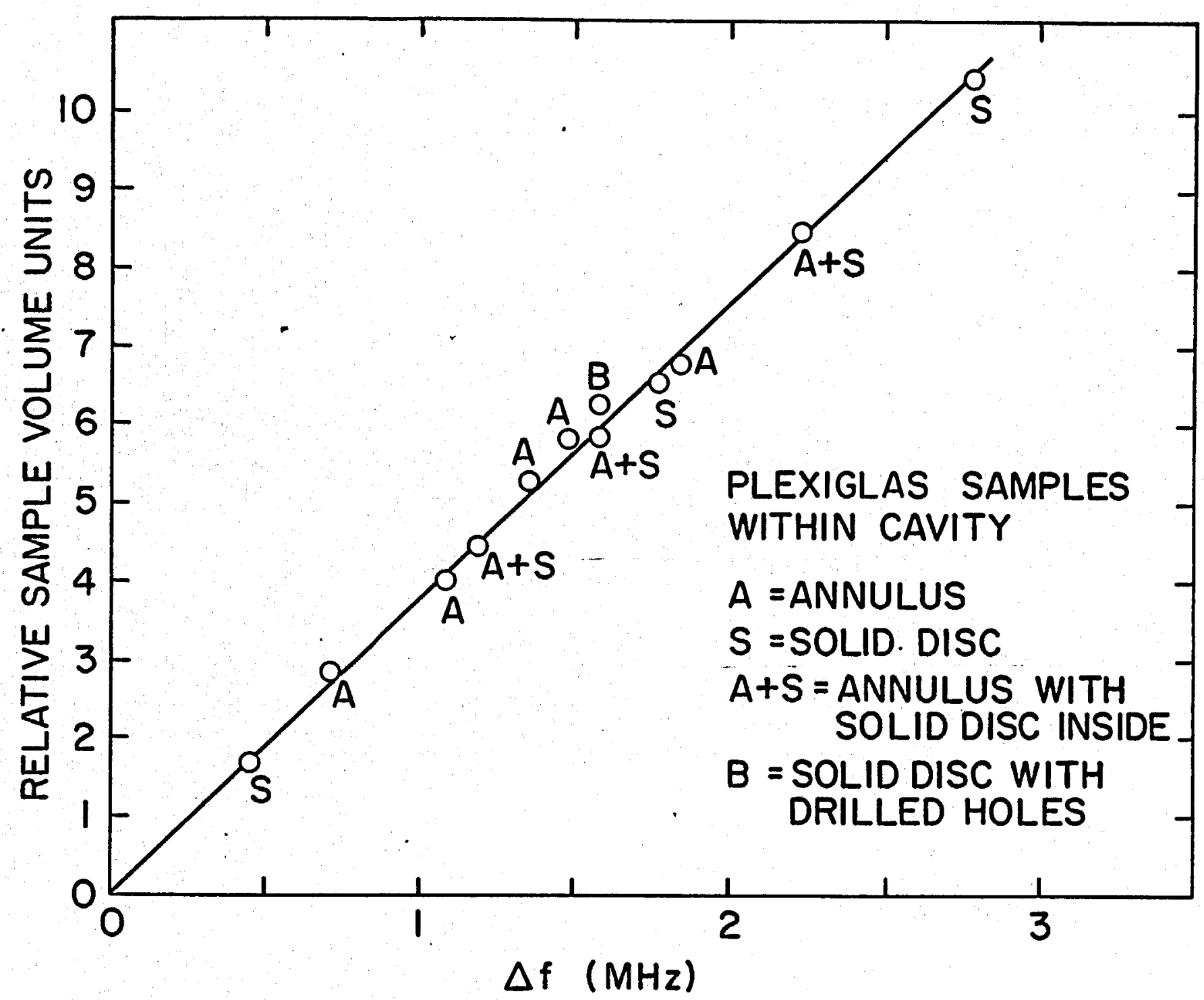

FIGURE 14

FREQUENCY SHIFT DUE TO PLEXIGLAS SAMPLE IN CAVITY. 


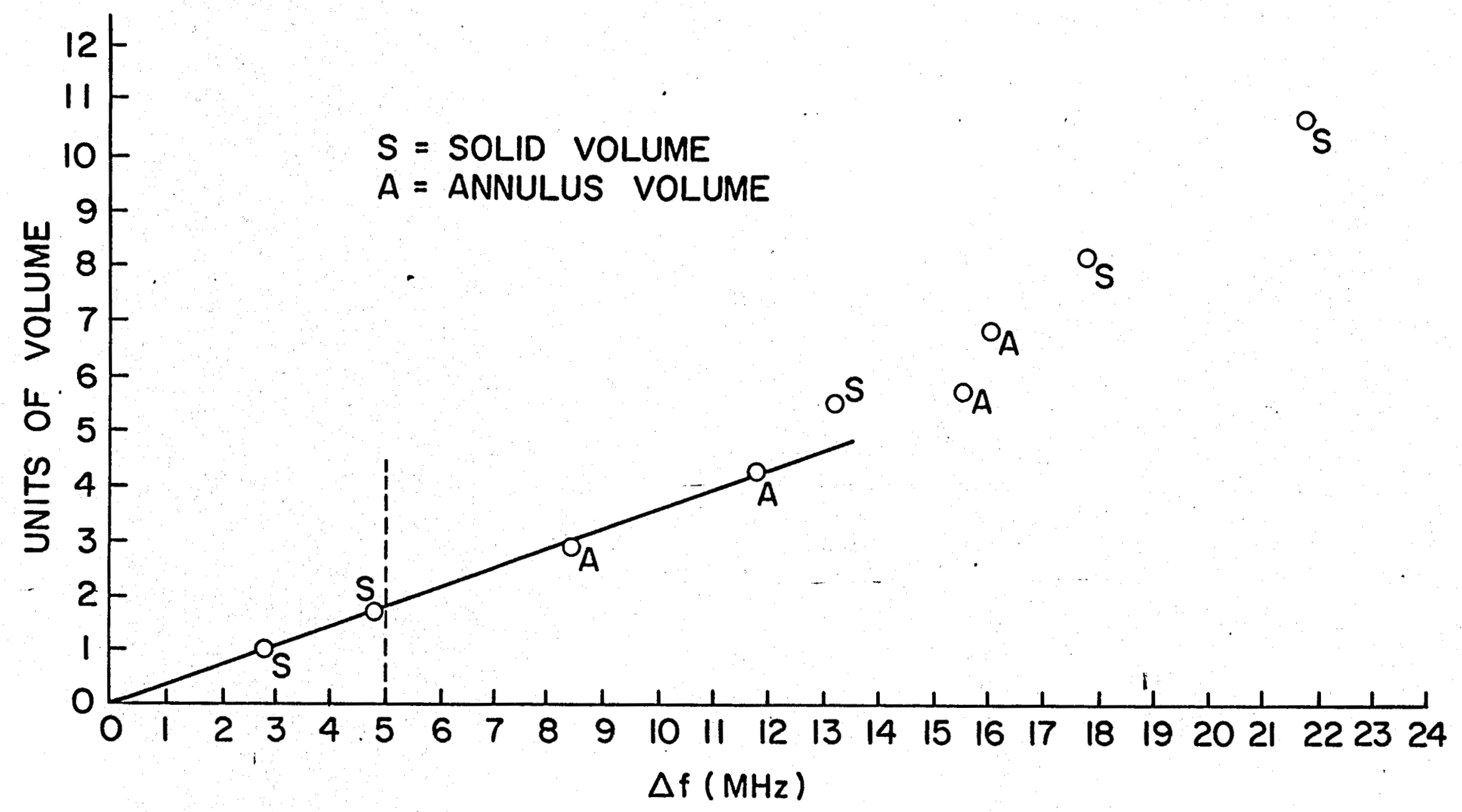

FIGURE 15

MEASUREMENTS MADE ON WATER FILLED SAMPLE VOLUMES INSIDE CAVITY.

(DATA CORRECTED FOR PLEXIGLAS CONTAINER) 


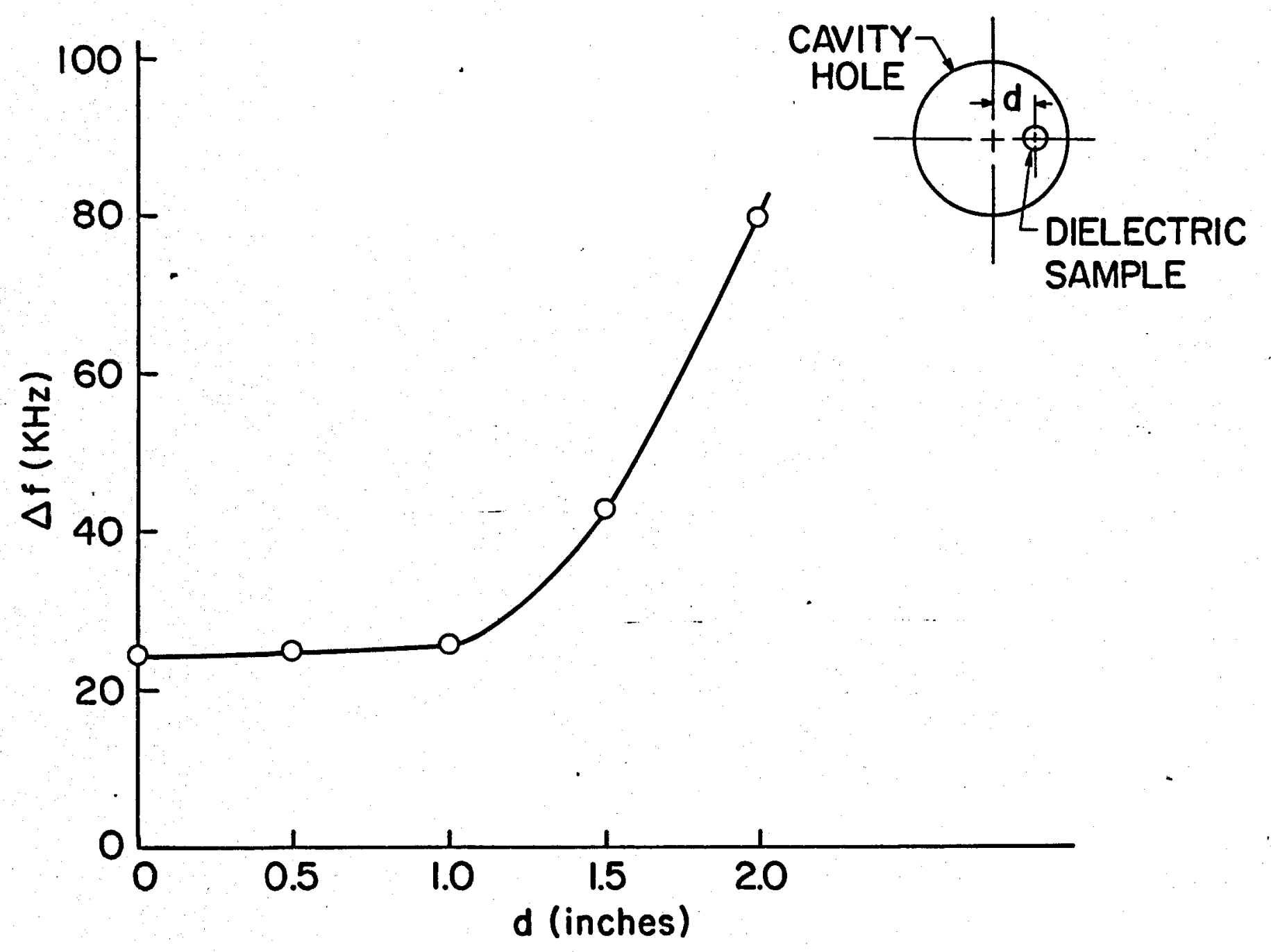

FIGURE 16

VARIATION OF FIELD STRENGTH

WITH POSITION IN CAVITY HOLE 


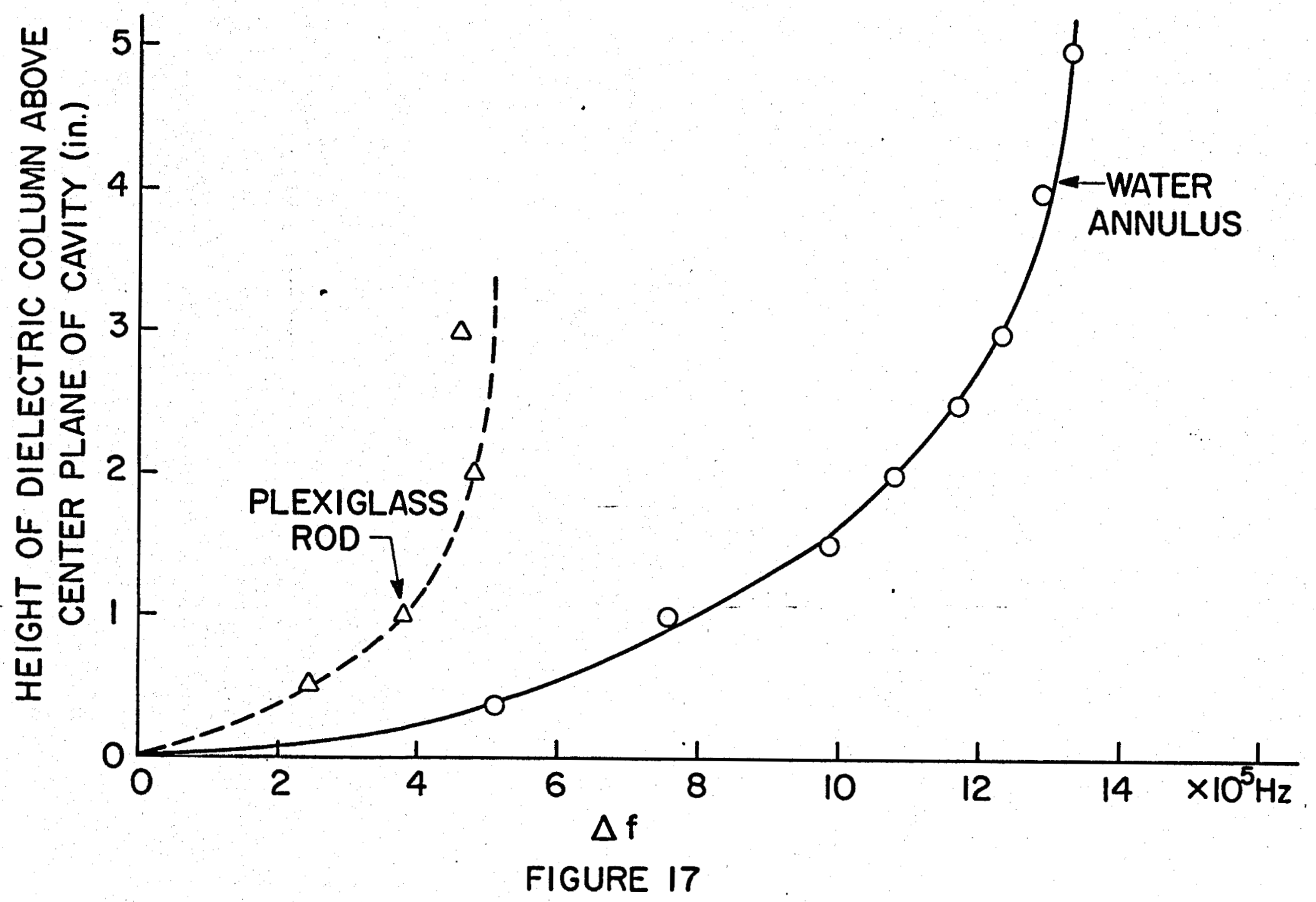

VARIATION OF FREQUENCY SHIFT WITH LOCATION OF DIELECTRIC OUTSIDE OF CAVITY WIDTH 